\title{
ForTificación ROMANa y MiNAS EN EL BaRRanco Abadejo (Paterna del Campo, Huelva)
}

\section{Roman fortification and mines in the Abadejo Barranco (Paterna del Campo, Huelva)}

Juan Aurelio Pérez Macías

RubÉn Macías Fortes

Manuel Rabadán VÁZqueZ

Universidad de Huelva

Recibido: 08/03/2019

Revisado: 04/04/2019
Aceptado: 30/05/2019

Publicado: 05/07/2019

\section{RESUMEN}

En este trabajo damos a conocer una nueva pequeña fortificación romana en término municipal de Paterna del Campo (Huelva, España). Se discute la funcionalidad de este tipo de castillos en Hispania y se estudia su entorno, en especial la riqueza minera de la comarca y las vías de comunicación, para concluir que formaba parte de un plan preconcebido de control del territorio para favorecer su explotación minera.

\section{Palabras Clave}

Roma; Fortificación; Minería; Comunicaciones; Control del territorio.

\section{ABSTRACT}

In this work we present a small Roman fortification located in the municipality of Paterna del Campo (Huelva, Spain). The functionality of this castles in Hispania is discussed and the environment is studied, especially the mining wealth of the region and the communication roads, to conclude that it was part of a preconceived plan of control of the territory to promove the mining exploitation.

\section{KEYWORDS}

Roma; Castle; Mining; Roads; Control of the territory.

japerez@uhu.es 
En un reciente trabajo hemos dado a conocer toda una serie de pequeñas fortificaciones romanas en la provincia de Huelva (Pérez Macías, 2018). El interés de este tipo de obras se ha relacionado en ocasiones con la necesidad de protección de las minas, una valoración que tenía que ver con su abundancia en el suroeste peninsular, donde existe un significativo número de yacimientos minerales, explotados en época romana para la producción de plata y cobre, en especial los situados en la Zona Geológica Surportuguesa, donde se extiende el distrito minero conocido como Faja Pirítica Ibérica. La importancia de esta zona es de sobra conocida desde los trabajos de C. Domergue (1990) y la Exploración Arqueometalúrgica de Huelva (Blanco y Rothenberg, 1981), y minas como Riotinto, Tharsis o Aljustrel, con sus inmensos escoriales, reflejos de su verdadera producción industrial, ejemplifican bastante bien la envergadura de la explotación minera de época romana.

En este trabajo que acabamos de citar pretendíamos estudiar la relación que pudiera existir entre ese conjunto de fortificaciones y la explotación minera, pues fortificaciones de idéntica tipología y cronología se conocen en otros lugares de Hispania (Moret y Chapa, 2004), e incluso algunos investigadores las han relacionado con los primeros signos de la colonización agrícola romana, como casas-fuertes, es decir como viviendas fortificadas de los colonos romanos que se aventuraban en la explotación de un territorio nuevo y no suficientemente pacificado, lo que hacía preciso estas obras de defensa (Moret, 1999). Ésa fue incluso la propuesta para la mejor conocida de ellas, la de Castelo de Lousa (Mourão, Portugal), que ha sido objeto de una nueva excavación con motivo de la construcción del embalse de Alqueva (Alarcão, Carvalho y Gonçalves, 2010).

Estas fortificaciones romanas del suroeste comenzaron a ser valoradas a partir de la publicación de las localizadas en el Bajo Alentejo (Maia, 1986) y por primera vez se indicaba que estaban relacionadas con la explotación minera. Esta propuesta estaba bien justificada, ya que se encontraban en unas comarcas que entraban de lleno en la Faja Pirítica Ibérica (Tornos Arroyo, 2008), cuya explotación industrial en época romana era ya conocida por los trabajos de los ingenieros y geólogos, en especial desde las analíticas de escorias realizadas por L. V Salkield (1970). Aunque no pudo relacionarse ninguno de estos castella con una mina concreta, sí parecía evidente que pudieron contribuir a la organización y control de este territorio minero. Después de esta primera publicación se ha incrementado de manera notable el número de fortificaciones, tanto en zonas mineras, como La Serena (Ortiz y Rodríguez, 2004), como en ámbitos más alejados, Alto Alentejo (Mataloto, 2002), la Vega del Guadiana (Mayoral et al., 2011), Alto Guadalquivir (Gutiérrez Soler, 2010), Murcia (Brotons y Murcia, 2008) y la Mancha (Morín et al., 2010). La realidad actual es que este tipo de pequeñas fortificaciones se extienden por los distintos territorios de Hispania y su implantación se inició en época republicana, como una respuesta a la necesidad de asegurar el territorio y las vías de comunicación ante los conflictos con las poblaciones autóctonas recias a la asimilación y también en momentos de peligro provocados por los enfrentamientos civiles que se desarrollaron en territorios de dominio romano a lo largo del siglo I a.C. (Mayoral y Celestino, 2010; Sala, Moratalla y Abad, 2014; Mataloto, Mayoral y Roque, 2014; Padrós y Ruiz de Arbulo, 2015; Pera y Vidal, 2016; Principal et al., 2017; Mayoral Herrera, 2018). Parece claro que este sistema de fortificaciones hay que explicarlo desde distintos puntos de vista, su cronología es amplia y su funcionalidad obedece a una gran variedad de situaciones para la protección del territorio en explotación (Heras Mora, 2018, 546 y ss).

En las comarcas que se encuentran en la zonas geológicas Surportuguesa (ZOM) y Ossa Morena (ZOM), que destacan por la abundancia de mineralizaciones ricas en cobre, plata, plomo y hierro, es evidente que este tipo de fortificaciones ayudaron a que la exploración, explotación y las comunicaciones pudieran desarrollarse en un clima de paz que auspiciara la colonización minera del territorio, tal como defiende C. Fabião (2002). Pero lo que late detrás de las mismas no es la extracción minera en sí, como refugios o casas-fuertes donde pudieran protegerse los colonos mineros de una concesión en un momento de peligro, sino como un mecanismo que ofreciera confianza a la iniciativa privada, ya que la riqueza minera que esto generaba y la complicada geografía donde se llevaba a cabo, que es el fondo del problema, podían desencadenar inseguridad en un período particularmente conflictivo por los enfrentamientos civiles, desmovilización de tropas y proliferación del bandidaje, bien recogió en las fuentes (Ad Familiares, 10,31,1).

Para nosotros, la situación de estas fortificaciones en la comarca onubense del Andévalo, precisamen- 
te donde alcanza mayor desarrollo la Faja Pirítica Ibérica, no se vincula directamente a la protección de los metalla, ya que ninguna de ellas se ubica en una mina, salvo la de cronología republicana documentada en las minas de Riotinto (Pérez y Delgado, 2010). Sin embargo, a nuestro modo de ver todo este conjunto de fortines pueden relacionarse con la militarización de este paisaje minero, para permitir un férreo control del territorio, estratégico desde el punto de vista económico para la colonización romana. Si bien es verdad que su distribución no está directamente relacionada con las minas, significan que Roma las concibió para afianzar la seguridad de esta zona minera, situándolas de este modo junto a algunas vías de comunicación que facilitaban el tránsito de los abastecimientos y personas que iban llegando a esta comarca como consecuencia de las grandes expectativas que alentaron los millones de toneladas de minerales que presentaban estas gigantescas masas polimetálicas del suroeste ibérico, y para evitar que zonas despobladas y de difícil acceso sirvieran de refugio a malhechores que podían entorpecer el amplio programa de exploración y explotación minera que comenzó a cristalizar en la segunda mitad del siglo I a.C. Con este momento coincide la construcción de toda una serie de fortificaciones, y su abandono a lo largo de la primera mitad del siglo I d.C. también es paralelo a la consolidación de los grandes poblados de este distrito minero, Riotinto (Urium), Tharsis (Rubrae), Aljustrel (Vipasca), entre otros, donde conocemos por los bronces de Aljustrel (VIP I, 3) que contaban con destacamentos de soldados, que desempeñarían las labores de policía (Domergue, 1983).

El estudio del entorno de la fortificación del Barranco Abadejo puede clarificarnos este panorama.

EL CASTELLUM ROMANO DE BARRANCO ABADEJO.

La fortificación romana se sitúa junto a la margen derecha del Barranco Abadejo, muy cercana a un conjunto de minas filonianas de sulfuros de cobre (figura 1), no inventariadas a lo largo de los trabajos de prospección que se han llevado a cabo en toda esta zona, aunque son perfectamente conocidas gracias a los trabajos de exploración minera que se realizaron en la segunda mitad del siglo XIX, recogidos en la obra de J. Gonzalo y Tarín, quien, como detallaremos más adelante, cita expresamente estos filones cupríferos de Barranco Abadejo.
El recinto fortificado se levantó sobre un cerro de escarpadas laderas, rodeado en el costado oriental por el Barranco Abadejo y en el occidental por otro barranco que confluye con el anterior en la parte meridional. Reúne, por tanto, buenas condiciones de defensa natural, protegido en tres de sus flancos por barrancadas y solo con un acceso cómodo por el lado septentrional. A pesar de ello, no es un cerro que destaque en el paisaje por sus cualidades de control visual, ya que se encuentra rodeado de cerros de mayor altura que impiden panorámicas que no superan los $300 \mathrm{~m}$. De este modo, consideramos que la fortificación se emplazó en una zona de sombra, sin posibilidades reales de control del territorio que le rodea, salvo para cualquier senda que utilizara el recorrido del Barranco Abadejo. Estas características topográficas son idénticas a las que hemos detectado en la mayor parte de los castillejos romanos que conocemos en la Sierra de Tejada y en la Rivera de Casa de Valverde (Pérez Macías, 2018).

La fortificación repite un esquema parecido al documentado en otros castillos romanos de la provincia de Huelva. Pueden definirse como recintos-torre, ya que su estructura está formada por una torre a la que se adosa un pequeño recinto fortificado de tendencia trapezoidal (figura 2). En el caso de la de Barranco Abadejo la torre se dispone en la parte más alta del cerro, y su planta puede seguirse en todo su extensión, pues la labor de los buscadores de tesoros ha excavado esta parte superior de la estructura y presenta unas dimensiones de 8,65 por $5,60 \mathrm{~m}$, con muros de un metro de espesor (figura 3). La torre está dividida al interior en dos compartimentos por un muro de un metro de anchura, una planta que tiene paralelos en el Castillejo de la Lapa en Valverde del Camino (Pérez Macías, 2018). De su cara suroeste arranca un muro de un metro de anchura en dirección a la zona donde confluyen los dos barrancos (figura 4) y a partir de un desarrollo en planta poligonal se va adaptando a la parte menos abrupta del cerro, hasta alcanzar el ángulo noroeste de la torre (figura 5). Los lados del polígono que forma el recinto tienes unas dimensiones de 6, 27, 16 y $17 \mathrm{~m}$. En el encuentro de dos de estos muros presenta una inflexión en ángulo recto, para adaptarse al terreno sorteando un afloramiento rocoso, un tipo de solución que hemos detectado también en otras fortificaciones de la provincia de Huelva, como los castella de Pico Teja en Almonaster la Real y Cerro Castillejo en Valverde del Camino, por citar dos ejemplos (Pérez Macías, 2018). 

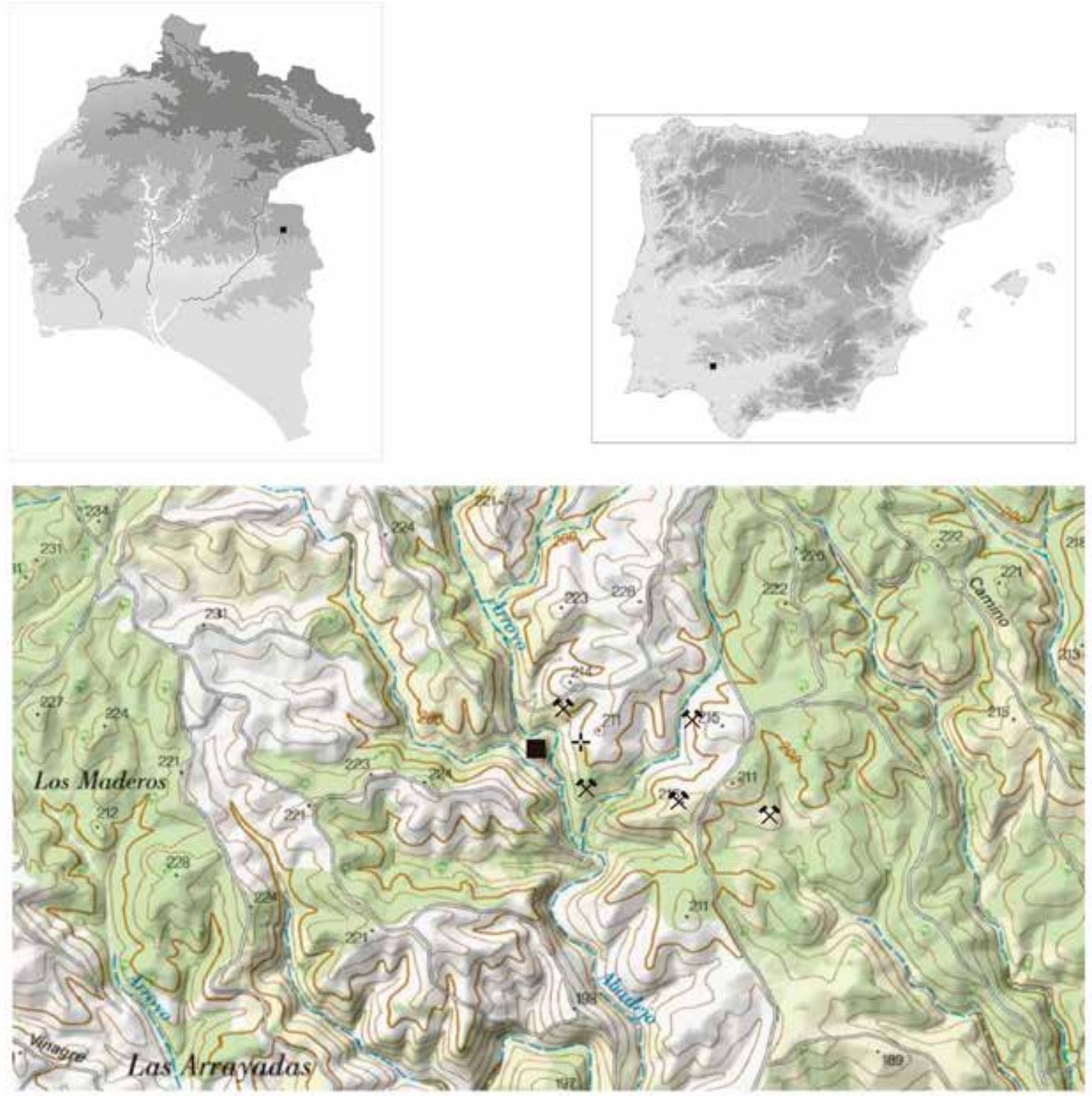

Figura 1. Situación de la fortificación del Barrranco Abadejo, fortificación romana y minas.

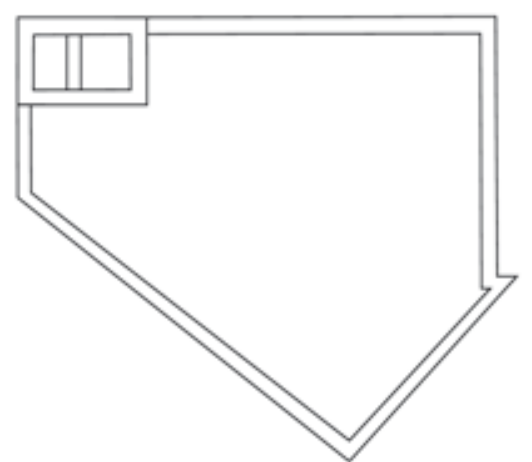

Figura 2. Croquis de planta de la fortificación de Barranco Abadejo.
Toda la obra está levantada en mampostería de lajas de pizarra con argamasa de barro. El uso de lanchas de pizarra permite hiladas casi horizontales que dotan a los muros de una gran estabilidad. Desde este punto de vista puede señalarse que su ejecución es muy cuidada (figura 6).

No se han localizado materiales de construcción romanos, ni ímbrices, ni tégulas, por lo que la cubierta de la torre debería estar formada por elementos vegetales. No se han registrado tampoco fragmentos cerámicos, salvo un posible galbo de ánfora, por lo que su cronología se ha establecido a partir de sus paralelos, con los que guardan unas evidentes semejanzas. 


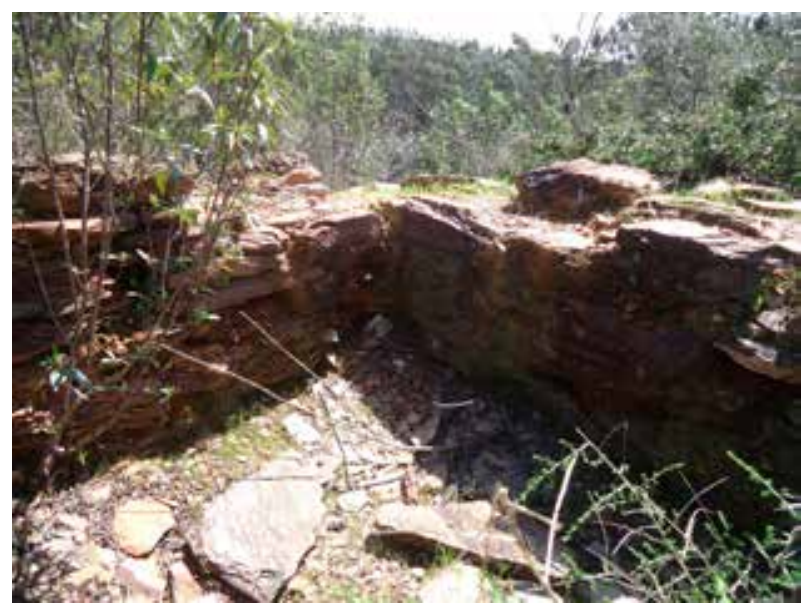

Figura 3.Restos de la torre de la fortificación de Barranco Abadejo.

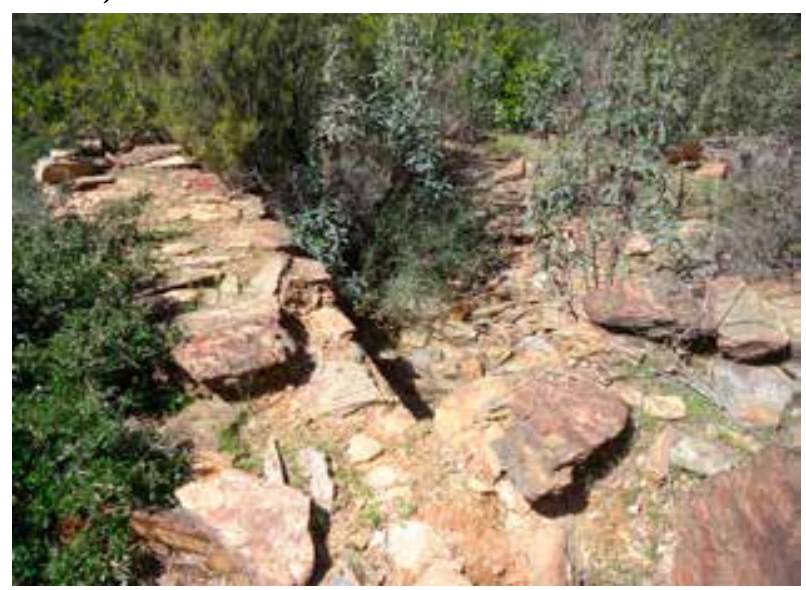

Figura 5. Muros de enlace de la torre y el recinto de la fortificación de Barranco Abadejo.

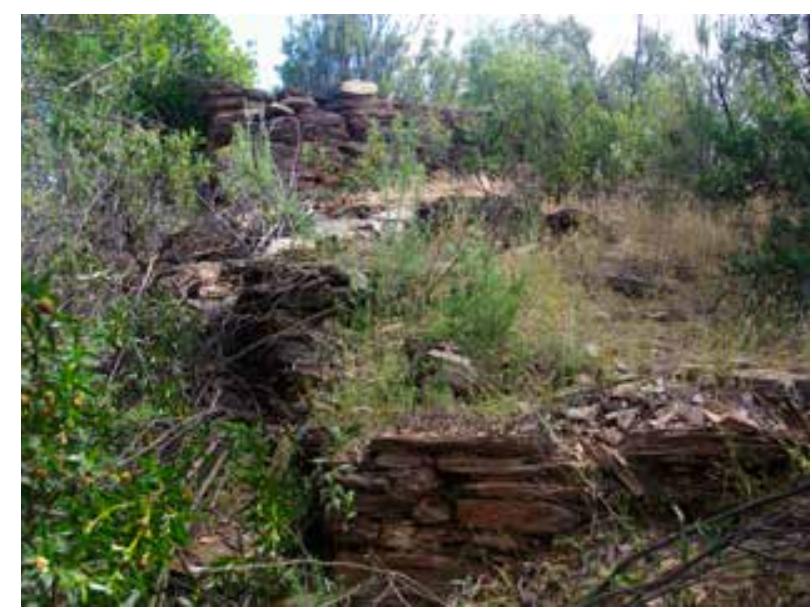

Figura 4. Muros del recinto de la fortificación de Barranco Abadejo.

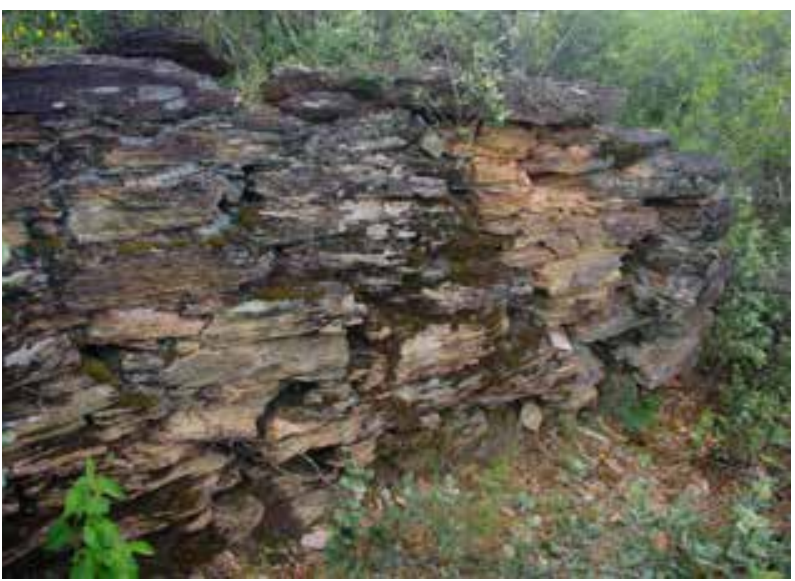

Figura 6. Detalla del aparejo de los muros de la fortificación de Barranco Abadejo.

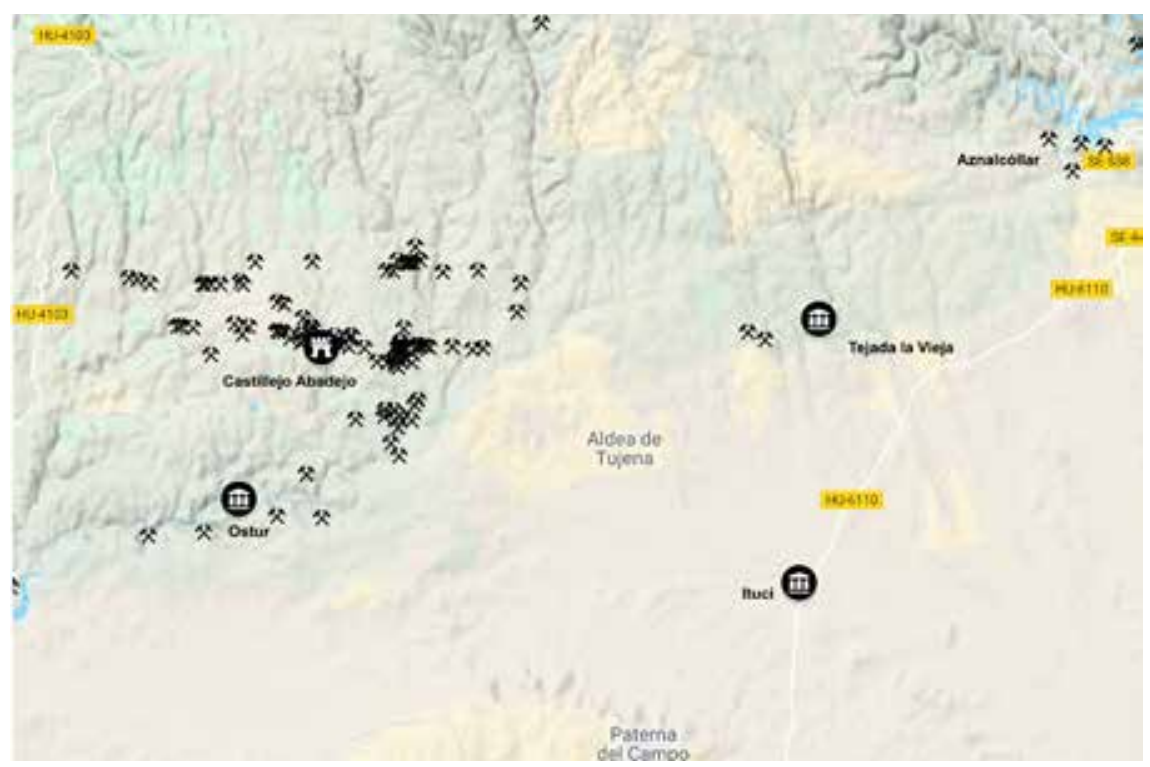

Figura 7. Fortificación de Barranco Abadejo, minas y yacimientos arqueológicos del entorno. 
Todo lo comentado hasta ahora viene a redundar en cuestiones que ya hemos referido anteriormente (Pérez Macías, 2018), en especial la existencia de un plan concienzudamente definido para la protección de este territorio, un plan del que son reflejo tanto los lugares elegidos para la construcción de estas fortificaciones, en zonas de relieve accidentado con pocas posibilidades de control visual, como la edilicia de las construcciones, que sigue un mismo patrón arquitectónico, una torre a la que se adosa un pequeño recinto en la ladera. A pesar de los escasos elementos de cronología relativa, también todas ellas parecen responder a una misma época, que se extiende a lo largo de la segunda mitad del siglo I a.C. hasta mediados del siglo I d.C., con especial incidencia en época augusto-tiberiana (Pérez Macías, 2015a). En cualquier caso, no parece que ninguna de ellas estuviera operativa en época flavia.

LAS MINAS DE LA SIERRA DE TEJADA Y RÍO CORUMBEL.

El conjunto de minas de esta zona está bien referenciado en la literatura minera de la provincia de Huelva, en especial en las obras de J. Gonzalo y Tarín (1888) y de I. Pinedo Vara (1963), pero, más allá de su caracterización general, su conocimiento geológico es bastante deficiente. Por otro lado, tampoco son abundantes los estudios arqueológicos de la zona, salvo las investigaciones realizadas en algunas de estas minas por la Exploración Arqueometalúrgica de Huelva en la zona de Gila (Blanco y Rothenberg, 1981) y M. Hunt Ortiz (2003) en el sector de El Corchito.

Su ubicación se sitúa en la parte meridional de la Zona Surportuguesa, en los terrenos paleozoicos de las primeras estribaciones de Sierra Morena, junto al contacto con la campiña terciaria de la Tierra Llana de Huelva, que formaba parte ya de la Depresión del Guadalquivir (Moreno, González y Sáez, 2009).

Como nota de la importancia del conjunto hay que apuntar en primer lugar que son campos filonianos que se extienden por parte de los términos municipales de Escacena del Campo, Paterna del Campo, Berrocal, Manzanilla, Villalba del Alcor y La Palma del Condado (figura 7). El elemento que les une es la cuenca del río Corumbel, afluente de la margen izquierda del río Tinto, al que se incorpora en las inmediaciones de la Palma del Condado. De ahí que Pinedo Vara identificara a parte de estas minas como Campo Filoniano del Río Corumbel
(Pinedo Vara, 1963, 526). Desde el punto de vista histórico parece más acertada la denominación de minas de la Sierra de Tejada, como las definió J. Gonzalo y Tarín (Gonzalo y Tarín, 1888, II, 599 y ss.). Efectivamente, todo este conjunto de minas se encuentran en lo que debieron ser los territorios de los antiguas ciudades romanas de Ostur (Mesa del Castillo, Manzanilla) e Ituci (Tejada la Nueva, Paterna del Campo/Escacena del Campo), que alcanzaron el estatuto municipal en época flavia (González y Pérez, 1986).

Dentro de las estructuras filonianas pueden diferenciarse dos grupos, los yacimientos de sulfuros de cobre, ricos en malaquita y calcopirita, aunque a veces se presentan otros ricos en cobre con buenas leyes de plomo, y los yacimientos de sulfuros complejos, ricos en galena.

Sobre los yacimientos de sulfuros de cobre de la Sierra de Tejada, que también se ha denominado sector del Alto Corumbel, son escasas las noticias, pues únicamente J. Gonzalo y Tarín ofrece información de estas mineralizaciones (Gonzalo y Tarín, 1988, II, 599 y ss.). El campo filoniano se desarrolla sobre pizarras silúricas y los filones son cuarcíticos, unas veces a favor de la estratificación y otras rompiendo los sedimentos de las pizarras. Consisten en vetas de cuarzo interestratificadas en pizarras silurianas, formados por óxidos de hierro y cobre y carbonatos de cobre en la parte superficial de las mineralizaciones y sulfuros de cobre en profundidad, a veces acompañados de sulfuros de plomo (galena) y zinc (blenda). Fueron minas donde se encontraron multitud de herramientas mineras prehistóricas, los martillos de piedra con surco central de enmangue (Gonzalo y Tarín, 1888, II, 20-21), testimonio de una intensa explotación durante la Edad del Bronce (Blanco y Rothenberg, 1981). Los filones se extienden en una superficie de unos $240 \mathrm{~km}$ cuadrados entre el curso del río Tinto, la Sierra de Rite y el Campo de Tejada. De su prospección contemporánea destaca "los innumerables pozos y calicatas", en las que abundan los martillos de piedra con surco central de enmangue que aparecían cuando se desatoraban las antiguas labores. $\mathrm{La}$ amplitud de este campo filoniano dio lugar a numerosas concesiones, entre las que Gonzalo y Tarín cita las de La Campana, Nueva, El Esquilón, La Fortuna, La Juana, El Pilángano, Nueva Pilángano, Esperanza de los Laureles, Nuestra Señora de los Dolores, San Antonio, Santa Ana, Espíritu Santo, San José, Colón, Santa Isabel, La Purísima Concep- 
ción, La Santísima Trinidad, La Virgen María, San Nicolás, San Antonio, San Javier, San Guillermo, Esperanza, Plotina Pompeya, Santa Teresa, etc. La mayor parte de las concesiones se prolongan por la margen derecha del río Corumbel hasta la zona de Cazullo en Berrocal. En total se han contabilizado unos 20 sectores filonianos. Un grupo numeroso de estos yacimientos de cobre se extiende entre la zona de la Barcita, Barranco Abadejo y la Tallisca, donde se han registrado un total de ocho yacimientos en una anchura de unos $500 \mathrm{~m}$, con corridas filonianas discontinuas que oscilan entre los $250 \mathrm{~m}$ y los $2 \mathrm{~km}$, y entre ellos se encuentran las concesiones Isabel (1200 m) y Colón (300 m). Las anchuras son variables, pero rondan entre los 0,5 y $1,50 \mathrm{~m}$. Otros filones se prolongan por la zona de Mancha de los Venados y Cumbre de las Navas.

Gonzalo y Tarín ofreció también las leyes de algunos de estos filones de cobre. Los de Barranco Abadejo alcanzan $14,00 \% \mathrm{Cu}, 14,00 \% \mathrm{~Pb}$ y $0,08 \%$ Ag. (8000 ppm Ag). En otros casos el mineral es más complejo, como algunas muestras de la concesión Isabel, una de ellas con 4,5\% Cu, 0,012\% Ag y $10,00 \% \mathrm{Zn}$, y otra con $34,00 \%$ As e indicios de cobre. Algunas minas arrojaron más riqueza, y entre ellas destaca la concesión Colón, en la que se alcanzaron los 49\% Cu y 0,11\% Ag. En la llamada Cueva del Monje el filón estaba formado por cuarzo con malaquita y calcopirita con una riqueza del $4,00 \% \mathrm{Cu}$, y en la concesión Espíritu Santo algunas muestras llegaron al 24\% Cu.

Estas minas de cobre también fueron investigadas por la Exploración Arqueometalúrgica de Huelva (Blanco y Rothenberg, 1981, 53 y ss.). En el Barranco de la Cueva del Monje se documentaron una serie de labores sobre filón en las que predominaban las rafas superficiales para el minado de los carbonatos superficiales de la zona de oxidación y dos pozos contemporáneos con sus correspondientes escombreras. Junto a las labores se encontraron algunas manchas de escorias, unas de diminuto tamaño y otras de escorias más viscosas. El mineral recogido en los vacies está formado por pizarra con costras de carbonatos de cobre (malaquita y azurita), con un enriquecimiento en cobre del $4,5 \% \mathrm{Cu}$ y buenos porcentajes también en hierro $(12,8 \% \mathrm{Fe})$ y sílice $\left(56,6 \% \mathrm{Si} \mathrm{O}_{2}\right)$. Las escorias más pequeñas tenían composición fayalítica, con $1 \% \mathrm{Cu}, 40 \% \mathrm{Fe}$ y 36,6\% $\mathrm{Si} \mathrm{O}_{2}$ e impurezas de arsénico (2500 ppm As) y Zinc $(0,28 \% \mathrm{Zn})$. Las escorias más grandes no diferían mucho en composición con las anteriores, pero eran más ricas en cobre, $2,3 \% \mathrm{Cu}$, el hierro era elevado, 47,3\% Fe, y el sílice bajo, 22,3\% $\mathrm{Si} \mathrm{O}$. También se consideraron modernos algunos fragmentos de escorias que no llegaron a estar fundidas, por lo que se interpretaron como resultado de una prueba de fundición. En este sector se recogieron también cerámicas a mano bruñidas "análogas a las de retícula bruñida" y galbos de contenedores a mano de carena alta y parte inferior del cuerpo con tratamiento de cepillado. Como conclusión se defendía una minería de la Edad del Cobre, con labores en trinchera y martillos de piedra con surco central de enmangue, una minería de la Edad del Hierro por las escorias más grandes, y una minería contemporánea representada por los vacies, pozos y escorias que eran producto de fundiciones de bondad. Sin embargo, la tipología de las labores, los martillos de piedra y las escorias pequeñas corresponden a una primera fase de explotación centrada en el Bronce Final, como indica la tipología cerámica, mientras que algunos pozos y las escorias de sangrado más grandes se pueden asignar a época romana; los pozos cuadrangulares y las escombreras sí pueden situarse en el período de fiebre minera vivido en la segunda mitad del siglo XIX. Por todo ello, tal como ya señaló Gonzalo y Tarín, estas minas fueron intensamente trabajadas en la prehistoria reciente (Bronce Final) y hubo intentos de extracción en época romana y contemporánea, pero no llegaron a cuajar en una verdadera fase de producción industrial. La explotación romana tampoco dejó en los alrededores estructuras perecederas, pues probablemente los mineros vivían en otros asentamientos, como Tejada la Nueva (Ituci), donde también existen evidencias metalúrgicas del tratamiento de minerales que podían proceder de esta zona (Vidal Teruel, 1997).

Las labores sobre filón en la zona de Junta de Gila también presentan muchas señales de laboreo prehistórico, sobre todo por la abundancia de minados en forma de trinchera que van siguiendo la dirección del filón y los numerosos martillos de piedra con surco central de enmangue que se encuentran en los alrededores. La mineralización está formada por brocantita, malaquita y óxido de hierro, $\mathrm{y}$ tiene buen tenor en cobre, $11,3 \% \mathrm{Cu}$. Dentro de las labores también se distinguieron minados romanos en las áreas 52B y 52C. La zona más interesante fue el denominado sector $52 \mathrm{~B}$, formado por labores de distintas épocas, dos pequeñas cortas con pozos alineados siguiendo la estructura filoniana, que deben 
adscribirse a época romana, aunque también fue explotada anteriormente en la Edad del Bronce, como ponen de manifiesto los martillos de piedra con surco central de enmangue que se han encontrado en los alrededores. Las labores romanas consistían en pozos pequeños de un metro cuadrado, que seguían la dirección de la mineralización e intentaron alcanzar la zona de enriquecimiento supergénico. Junto a las labores de trinchera y pozos también se documentaron pequeñas cortas, probablemente del siglo XIX. Las escorias son fayalíticas, con adición intencional de sílice y hierro como fundentes, $\mathrm{y}$ destacan sobre todo por el alto porcentaje de cobre, $4,5 \% \mathrm{Cu}, 42.9 \%$ Fe y $31,5 \% \mathrm{Si} \mathrm{O}_{2}$. En algunas escorias se detectaron impurezas de arsénico (2500 ppm As) y Zinc (1,04\% Zn). Las cerámicas se ajustan a los tipos característicos del Bronce Final meridional (Ruiz Mata, 1995), las cazuelas de carena alta y borde saliente, fabricadas a mano y cuidadosamente bruñidas. También se recogieron algunos fragmentos de cerámica romana de cocina.

M. Hunt Ortiz exploró posteriormente toda la zona entre la Pasada del Campanillero y la Pasada de Zalamea, los sectores de El Corchito y Gila, donde se identificaron 15 zonas de trabajo minero (Hunt Ortiz, 2003, 79 y ss.). Las mineralizaciones estaban formadas por filones de cuarzo con óxidos de hierro y carbonatos de cobre.

Dentro de las evidencias mineras de la zona de El Corchito se documentaron las siguientes labores: trincheras con pozos de sección rectangular (Mina 1), con materiales significativos, como los martillos de piedra con surco central de enmangue; trincheras de 1,5 $\mathrm{m}$ de anchura (Mina 2), con martillos de piedra con surco central de enmangue; trincheras con martillos de piedra con surco central de enmangue (Mina 3); trinchera de 0,80 $\mathrm{m}$ de anchura, con martillos de piedra con surco central de enmangue (Mina 4).

En la zona de Gila se prospectaron minas que no habían sido inventariadas en la Exploración Arqueometalúrgica de Huelva. Entre ellas se encuentran la Mina 8, que está formada por una serie de pozos de perfil inclinado, sección cuadrangular o subcircular de un metro de lado o un metro de diámetro. En sus alrededores se encontraron algunos fragmentos de martillos de piedra con surco central de enmangue. Muy cerca se sitúa la Mina 9, formada por una pequeña corta al aire libre, con martillos de piedra con surco central de enmangue, escorias de pequeño formato y un fragmento de crisol. El análisis del crisol en la zona de Gila arrojó riqueza en hierro $(54,48 \% \mathrm{Fe})$ y cobre $(40,39 \% \mathrm{Cu})$, y buenos contenidos de plomo $(4,8 \% \mathrm{~Pb})$ y plata $(0,019 \%$ $\mathrm{Ag})$. La Mina 11 es otra pequeña corta en la que abundan los martillos de piedra con surco central de enmangue, e igual sucede con la Mina 13, otra pequeña corta junto a la cual se han recogido martillos de piedra con surco central de enmangue y pequeños nódulos de escorias. Mayores dimensiones tiene la corta que forma la Mina 14 , de 20 por 5 $\mathrm{m}$, en cuyos alrededores se encontraron también algunos fragmentos de martillos de piedra con surco central de enmangue. Las minas 6,7, 10, 12, 15 y 16 eran minas que fueron muestreadas por la Exploración Arqueometalúrgica de Huelva.

Este campo filoniano continúa dentro del término municipal de Escacena del Campo, y en este sector destaca la mineralización de la zona de Santa Ana, donde se solicitaron las concesiones de Mina Trinidad y Mina del Carmen (Pinedo Vara, 1963, 487; Domergue, 1987, 228; Hunt Ortiz, 2003, 96). La mineralización está formada por vetas de cuarzo ricas en calcopirita que se extienden en una distancia de 150 a $300 \mathrm{~m}$. Se han identificado hasta cinco filones paralelos con potencias que pueden alcanzar los $65 \mathrm{~cm}$. Algunas muestras analizadas han ofrecido una riqueza de $16 \% \mathrm{Cu}$. Pinedo Vara resalta que a lo largo de estos filones hay varios pozos de profundidad variable, "algunos de estos de procedencia romana o tartésica”. Su explotación contemporánea se inició en 1929-1930, pero los trabajos de mayor calado se realizaron por la compañía Sociedad Española de Construcciones Electromecánicas (SECEM) entre los años 1944 y 1946, que extrajo unas 150 toneladas de mineral con unas leyes del 16\% Cu. Después se abandonaron los trabajos ante la bajada de las leyes de cobre. En los alrededores no se encuentran señales de laboreo metalúrgico de época prehistórica o romana.

En resumen, la escasa entidad de estos yacimientos filonianos de cobre de la Sierra de Tejada no terminó en una verdadera extracción industrial, y la minería quedó reducida a una fase de exploración, a la que responden las pequeñas manchas de escorias que se encuentran junto a las zonas de exploración y en la zona conocida como El Corchito, donde parece que hubo una fase de explotación más prolongada; su proximidad a la riberas del Corumbel pudo facilitar que se eligiera como el lugar de reducción de todas estas zonas de exploración que se estaban llevando a cabo en los alrededores. 


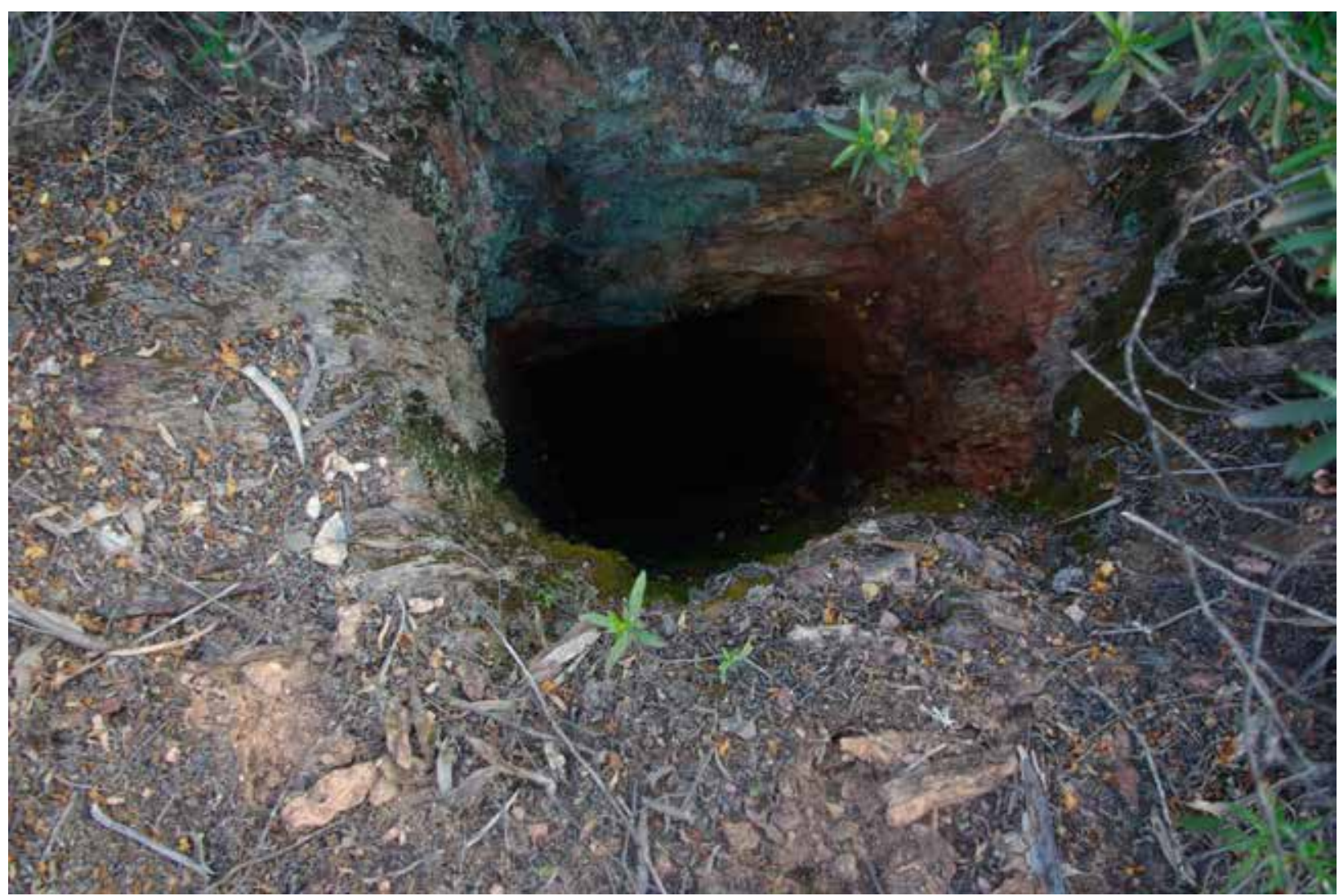

Figura 8. Pozos de exploración romanos en la inmediaciones de Barranco Abadejo.

Todas estas minas del río Corumbel beneficiaron los carbonatos superficiales, ya muy minados en el Bronce Final, y los intentos para localizar a mayores profundidades, por medio de pozos, una zona más rica de los minerales de la zona cementación, resultaron fallidas. La explotación romana de estos filones de cobre fue muy reducida, pues solo se han documentado algunos montones de escorias en los alrededores de la Cueva del Monje y El Corchito. Las labores modernas solo se dedicaron a la limpieza de las labores prehistóricas y romanas. Son por todo esto un conjunto de minas que distan mucho de los volúmenes de reservas de las minas polimetálicas de la Faja Pirítica Ibérica, cuyas formaciones en masa superan en dimensiones y tonelajes a estas pequeñas minas filonianas de sulfuros de cobre. En realidad, no pensamos que se desarrollara una verdadera fase de extracción en estas pequeñas minas del río Corumbel, pues la falta de verdaderos escoriales así lo indica, y a lo más cabe plantear una intensa exploración siguiendo las huellas de explotación prehistórica. Las labores romanas en forma de pozos intentaron alcanzar zonas más profundas de estas mineralizaciones a la búsqueda de la zona de cementación de sulfuros de cobre (enriquecimiento secundario), donde se encontrarían los minerales de más altas leyes en cobre, pero el resultado no sería el esperado.

Dada la abundancia de sectores de exploración minera en toda esta zona, no extraña que junto a la fortificación del Barranco Abadejo existan también evidencias claras de ese laboreo romano. La fortificación se encuentra en este sector de los filones de sulfuros de cobre y está rodeada de labores de extracción de época prehistórica y romana. Al oeste del recinto fortificado se encuentra una pequeña labor de exploración de fines del siglo XIX. Es una labor muy superficial que dejó sobre el terreno una pequeña escombrera, resultado probable del desescombro de los minados romanos de exploración, de los que son reconocibles una hilera de pozos de tendencia subcircular con unas dimensiones regulares de un metro de diámetro (figura 8). En su mayor parte se encuentran atorados a partir de los cinco o seis metros de profundidad, pero debieron ser más profundos en origen, para alcanzar el enriquecimiento supergénico a la búsqueda de minerales de cobre de altas leyes 


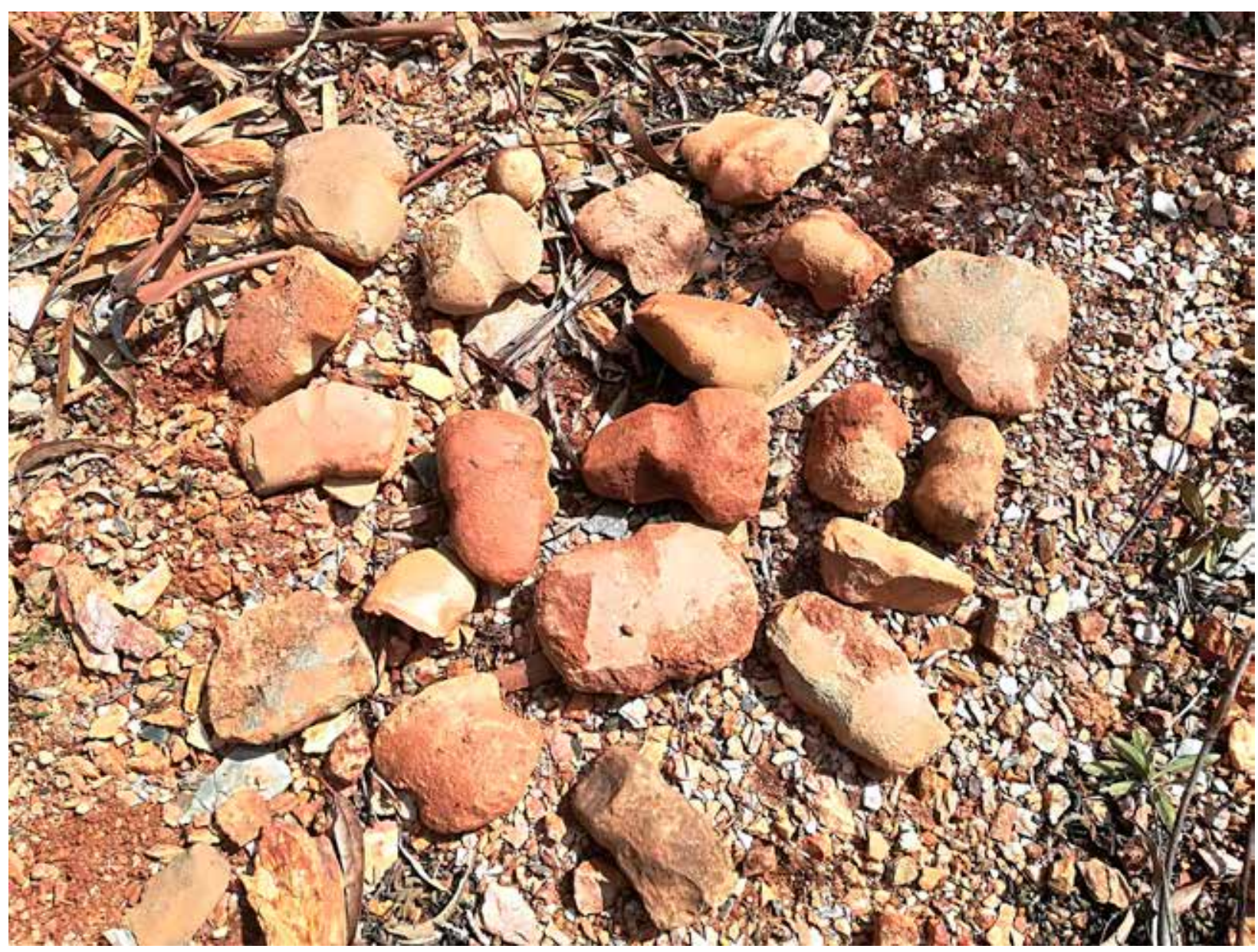

Figura 9. Martillos prehistóricos de mina en los filones cercanos a Barranco Abadejo.

(calcosina, covelina, melaconita, etc.). Tanto en las escombreras modernas como en los alrededores de los pozos romanos abundan los fragmentos de pizarra con costras de carbonatos de cobre (malaquita), que debían ser la señal para iniciar la exploración a mayores profundidades, $\mathrm{y}$ junto a estos fragmentos de los minerales explotados también hemos encontrado martillos de piedra con surco central de enmangue (figura 9), otra prueba más de la intensa explotación a que estuvo sometido todo este campo filoniano de sulfuros de cobre de la Sierra de Tejada a fines de la Edad del Bronce.

Algo más separados de la fortificación se encuentran otras dos zonas de explotación antigua. Una de ellas, al suroeste, es otra rafa en la que se ha abierto un pozo de exploración en época contemporánea. En las escombreras del pozo y los alrededores aparecen algunos martillos de piedra con surco central de enmangue, pero no hemos llegado a distinguir labores romanas, que deben haber sido destruidas por los aterrazamientos de la repoblación de eucaliptos.

Más al norte también existe otra pequeña zona de trabajo contemporáneo casi a la orilla de otro de los barrancos que van a dar aguas al Barranco Abadejo $\mathrm{y}$ al otro lado de la vaguada se encuentran tres pozos romanos de tendencia cuadrangular, colmatados de sedimentos casi hasta dos metros de la embocadura.

Más lejos aún también se distinguen otras escombreras entre las terrazas de las plantaciones de eucaliptos, y todas estas evidencias próximas al Barranco Abadejo parecen mostrar la existencia de dos filones paralelos de orientación sureste-noroeste de trayectoria discontinua. En todas las escombreras se encuentran muestras de pizarra con costras de malaquita y azurita, que debieron ser los fósiles directores que guiaron la exploración minera tanto en la antigüedad como en época contemporánea.

Son pues muchas las evidencias mineras antiguas y contemporáneas que se encuentran en todo este 
sector de la Sierra de Tejada. También son abundantes en la zona conocida como Los Maderos, donde se han encontrado también muchas manifestaciones filonianas de sulfuros de cobre con señales de minería antigua en forma de pozos de tendencia cuadrangular, rafas superficiales, y martillos de piedra con surco central de enmangue. En una exploración realizada en los años 80 del siglo XX por el Departamento de Exploración Minera de Riotinto Minera S.A., se recogieron multitud de martillos de piedra con surco central de enmangue, que fueron depositados posteriormente en el Museo Minero de Riotinto por D. Nestavo Centeno. Más al oeste, pero muy próximas, siguen estas manifestaciones filonianas en la zona de Dehesa del Vinagre, junto al Arrojo del Huerto Mateo, donde también abundan los martillos de piedra con surco central de enmangue, hileras de pozos cuadrangulares de un metro de lado y fragmentos de malaquita en las escombreras.

Al sur de estos yacimientos cobrizos de la margen derecha del río Corumbel se encuentra el segundo grupo de minas filonianas de sulfuros complejos, en las que predomina el plomo, identificadas como minas de Bajo Corumbel. Estos yacimientos fueron considerados plomizos por J. Gonzalo y Tarín (1888, II, 608 y ss.), quien destacó su riqueza en galena, más o menos argentífera, y en menor cantidad en blenda. Unas veces están alineados a las bandas de pizarra y en otras ocasiones cortan la estratificación. La forma de los yacimientos es similar a los de la zona septentrional de la Sierra de Tejada, filoncillos discontinuos de composición muy variable, sobre todo en lo que respecta a la plata que contienen.

Los estudios geológicos más recientes sobre los filones de sulfuros complejos inciden en la importancia de este campo filoniano y en la complejidad de sus mineralizaciones por sus valores de Sn-W-As (Sáez et $a l .$, 1989). En la zona de la Palma del Condado la mineralización presenta tres zonas y es la interna la que contiene cuarzo con sulfuros y carbonatos. Su origen se sitúa en época tardohercínica a favor de densa red de mesofracturas, que se producen en zonas de cizalla superficiales. Las mineralizaciones están formadas por tres series de filones, aunque no siempre se constatan. Sus espesores son variables, entre los 2 y $10 \mathrm{~cm}$ de potencia y sus recorridos no sobrepasan los $50 \mathrm{~m}$.

Muchas de estas minas de sulfuros complejos se trabajaron a comienzos del siglo XX por una sociedad denominada Minas del Corumbel, y entre las concesiones destacaron las de Las Completas, Flo- rida y Nuestra Señora del Amparo (Pinedo Vara, 1963, 531 y ss.).

Los primeros trabajos en Las Completas se iniciaron en 1871 sobre un filón de cuarzo rico en galena, y después se hizo cargo de su explotación la Compañía Francesa de Plomo del Corumbel, que trabajó entre los años 1892 y 1909, cuando paralizó sus extracciones ante la bajada del precio del plomo. Las potencias del filón oscilaban entre los 8 y $12 \mathrm{~cm}$, sus leyes se han estimado en un $70 \% \mathrm{~Pb}$, y una riqueza en plata de unos 1000 gramos a la tonelada de mineral.

La mina Florida se encuentra al sur, en la margen del Barranco Ravalejo, y está formada también por un filón de cuarzo con una potencia de unos $40 \mathrm{~cm}$. Parece ser que fue explotada en época romana, ya que durante su explotación contemporánea se descubrieron grandes huecos en su interior, y después de su desescombro se recuperaron varias vasijas de bronces y algunos instrumentos de hierro junto a fragmentos de minerales complejos (Pinedo Vara, 1963, 530).

La concesión Nuestra Señora del Amparo se encuentra en la zona oriental de la corrida filoniana. Algunos mantos de escorias evidencian también su explotación en época romana. Los trabajos contemporáneos comenzaron con la compañía creada por las familias Sundheim y Doestch, pero los trabajos se paralizaron en el año 1880. Según Prieto y Vargas las leyes eran buenas, pero se desconoce el porcentaje de sus contenidos (Pinedo Vara, 1963, 532).

Otra zona de explotación contemporánea es la mina Honda. Su filón está formado por galena, blenda, pirita y calcopirita en ganga de cuarzo. Algunas muestras ofrecieron hasta un $2 \% \mathrm{Cu}$ (Pinedo Vara, 1963, 531).

En algún caso las galenas son argentíferas y se han encontrado asociadas a escorias de sílice libre de época protohistórica, pero no fue una explotación de envergadura dada la poca entidad de estas estructuras filonianas, de buenos recorridos, pero de escasa potencia.

Algunas consideraciones.

Hemos de anotar que la fortificación de Barranco Abadejo no se encuentra aislada en este territorio de minas. La Sierra de Tejada, el tramo serrano entre los municipios de Paterna del Campo y Berrocal, situada en el triángulo entre los ríos Tinto y Corumbel, es una de las zonas de la provincia con mayor número de fortificaciones romanas. 
El interés de esta comarca se remonta a época Orientalizante, momento en el que el oppidum de Tejada la Vieja debería ser el lugar central de todo este territorio (Fernández Jurado, 1989). Las primeras investigaciones en la ciudad destacaron la relación de este asentamiento con la metalurgia de la plata (Blanco y Rothenberg, 1981, 229 y ss.; Fernández Jurado, 1989), en lo que se consideró entonces una salida de los minerales de Riotinto hacia la campiña y marismas del Guadalquivir. Estudios posteriores en el asentamiento de San Bartolomé de Almonte propusieron que los minerales de Tejada la Vieja y San Bartolomé no procedían de Riotinto, sino de Aznalcóllar, también explotada en época Orientalizante (Hunt Ortiz, 1995), que se ve desde el mismo yacimiento de Tejada la Vieja, y se canalizaban a través de San Bartolomé hacia las marismas de la Rocina en dirección al asentamiento fenicio de Cádiz (Ruiz y Fernández, 1988). Después de la crisis de la minería en el siglo VI a.C. se produjo el traslado de la población hacia el nuevo enclave de Tejada la Nueva, mejor situada en las tierras de campiña para la explotación agrícola, y este nuevo asentamiento, que acuñó moneda a nombre de Ituci, alcanzaría el rango municipal en época flavia y perduraría hasta comienzos de la edad moderna (Vidal Teruel, 1997). Qué duda cabe que la situación del denominado posteriormente como Campo de Tejada, a caballo entre dos zonas mineras importante, Riotinto y Aznalcóllar, contribuyó a que el asentamiento ocupara una posición crucial en las comunicación con estas dos minas.

Después del abandono de Tejada la Vieja, su posición estratégica quedó confirmada por la construcción de un fortín romano en Los Castrejones, junto a las murallas de esta ciudad protohistórica, cuyos materiales remiten a comienzos del siglo I a.C. (Rufete Tomico, 2009). Esta fortificación es pues la primera evidencia de la importancia que otorgó Roma a la protección de este territorio, cuyo control fue clave durante la guerra lusitana de Viriato, quien exhortó a las habitantes de Ituci a tomar partido por la rebelión contra el ejército de ocupación romano, acuartelado en Italica (Canto, 1979).

En época tardorrepublicana y comienzos de la Era se construyen nuevas fortificaciones, entre ellas Los Pájaros/la Jarrita (Escacena del Campo), Los Perros (Escacena del Campo) y Collado del Cacho/los Atajuelos (Escacena del Campo), y ya en término de Berrocal las de Hoyo del Tío Benito y
El Cabo. También en Berrocal, pero un poco más alejadas, se encuentran las de Juan de Aracena, Castrejón de la Herradura, Castrejón de la Naja y Pico del Drago. La concentración de todas estas fortificaciones en lo que ha sido denominada la Sierra de Tejada debe tener una significación.

¿Estuvo relacionada la fortificación del Barranco Abadejo con todo este conjunto de labores mineras de exploración que hemos inventariado en sus alrededores? A primera vista parecería que sí, pero una vez que estudiamos todas las fortificaciones de la zona no resulta tan evidente esa relación directa (figura 12). No parece desde luego que estemos en presencia de una casa-fuerte de los mineros o de las compañías que llevaban a cabo la exploración minera de la zona, pues en el resto de las fortificaciones no se presenta esa ecuación de mina y recinto fortificado. Estos castella debieron tener otra funcionalidad, aunque se encontraban de lleno en el sector de las mineralizaciones de cobre de la Sierra de Tejada, perfectamente definido desde el punto de vista geográfico por J. Gonzalo y Tarín. No se encuentran protegiendo cada una de las formaciones filonianas. Pero no por ello puede deducirse que no tengan que ver con la minería, ya que se encuentran concentradas precisamente en la zona donde predominan este tipo de manifestaciones mineras. Es por ello que pensamos que se levantaron para controlar este territorio, demasiado abrupto para poder vigilarlo desde un solo asentamiento, es decir, para dar cobertura y seguridad al despliegue de una exploración minera que se interesó por todos y cada uno de esos filones, aunque después esta labor inicial el trabajo desarrollado no ofreciera los frutos que se estaban obteniendo en otras minas de la Faja Pirítica Ibérica, como la de Riotinto, situada a menos de $30 \mathrm{~km}$ de distancia. Demostrarlo no parece tarea difícil, porque su implantación territorial nos ofrece los límites que tiene el territorio en el que se extiende esas mineralizaciones de cobre, que en expresión de J. Gonzalo y Tarín abundaban en las sierras que se prolongan entre el Río Corumbel, un límite que viene marcado por los castella de Barranco Abadejo, Los Pájaros/La Jarrita y los Perros, y el Río Tinto, donde se encuentra el Pico del Drago. Otro límite claro está representado por las fortificaciones de la Rivera del Gallego, Valle Quebrado, El Cabo, Hoyo del Tío Benito y Collado del Cacho/Atajuelos. Al interior de este territorio la red de vigilancia se completó con otros castella en los barrancos que atraviesan la zona, la Rivera 
del Hornueco, donde se encuentra el Castrejón de La Herradura, y el Barranco de la Naja, en el que se construyeron los de Castrejón de la Naja y Castrejón de Juan de Aracena. La proximidad al coto minero de Riotinto, que debía incorporar además otras minas de los alrededores, como Peña de Hierro, Chaparrita y Poderosa (Pérez y Delgado, 2012), y la abundancia de pequeños yacimientos filonianos eran razones suficientes para este programa de fortificación. Era, además, una zona de nulo rendimiento agrícola y de relieve escabroso, formada por una sucesión continua de profundos barrancos, un territorio idóneo para la acción de los malhechores, que podían aprovechar esas condiciones orográficas y su alejamiento de los núcleos de población para asaltar las comunicaciones de las minas más importante, como Riotinto, con las ciudades de la campiña, en especial Tejada la Nueva. En definitiva, fueron toda esta serie de factores los que propiciaron y obligaron a llevar a cabo este minucioso plan de control del territorio a partir de la construcción de estas pequeñas fortificaciones en lugares estratégicos del paisaje. En el fondo se estaba protegiendo el desarrollo de la prospección minera, que desde la segunda mitad del siglo I a.C. estaba explorando de manera muy planificada todos los sectores filonianos, por muy pequeños que éstos fueran.

Pero no debemos dejar de lado otra circunstancia detectada en el emplazamiento de estos fortines romanos. En otros casos se construyen en lugares estratégicos en las vías de comunicación, como los vados, en el que encuentran los casos de Los Castillitos en el vado del Odiel aguas arriba de Gibraleón y en el vado del Odiel en el camino de Riotinto a Aracena, o a lo largo de las vías que fueron recogidas por las fuentes, como el Pico Teja en la vía de Riotinto (Urium) hacia Aroche (Arucci), que se dirigía finalmente a Beja (Pax Iulia).

En no pocas ocasiones la Sierra de Tejada ha sido considerada como una zona de paso que comunicaba la cuenca minera de Riotinto con la ciudad de Tejada la Vieja primero y con Tejada la Nueva después. Es una propuesta que tenía como fondo la salida de minerales hacia la campiña y desde aquí a las marismas y desembocadura del Guadalquivir. Este planteamiento surgió a partir del hallazgo de abundantes escorias de plata (sílice libre) en el asentamiento de Tejada la Vieja (Blanco y Rothenberg, 1981, 231), y se llevaba el camino por la Pata del Caballo, que era atravesada por el paso de La Garganta en dirección a Berrocal y desde este punto a Riotinto. Sin em- bargo, este recorrido se aleja de una ruta directa a Riotinto. Además, las investigaciones en la mina de Aznalcóllar, a menos de $8 \mathrm{~km}$ de Tejada la Vieja, han demostrado que fue una mina importante durante el período Orientalizante (Hunt Ortiz, 1995), y en ella abundan así mismo las escorias de sílice libre de plata, por lo que es más coherente concluir que el mineral de plata que se fundía en Tejada la Vieja procediera de la inmediata mina de Aznalcóllar.

Pero la propuesta de este camino también ha tenido como argumentos los numerosos "carriles" tallados en el substrato de pizarra que se dirigen desde la zona de Tejada la Nueva y Paterna del Campo hacia Berrocal, donde se mantienen muchos tramos en perfecto estado de conservación. Dada la envergadura de la obra, hemos supuesto durante mucho tiempo que eran vías romanas que comunicaban la mina de Riotinto (Urium) con Tejada la Nueva (Ituci), de donde podía llegar parte del abastecimiento alimentario que se necesitaba en la cuenca minera, cuyos suelos son raquíticos y ácidos para la producción de aceite, cereal o vino (González y Pérez, 1986, 254; Ruiz Acevedo, 1998, 94). Este camino es también conocido como Camino del Moro y la tradición popular lo considera de época romana, para enlazar la zona del Campo de Tejada con la Cuenca Minera de Riotinto. Tras el estudio del camino romano de Riotinto a Huelva (Pérez Macías, 2015b), la vía que comunicaba la mina más importante de la Faja Pirítica Ibérica en época romana con el que había sido el puerto de embarque más utilizado desde época tartésica, este "carril" debe ser objeto de revisión. Los caminos romanos de la zona son vías encarriladas que conservan los surcos provocados por el roce de las llantas de hierro de las ruedas de los carros, mientras estos caminos de la zona de Paterna del Campo a Berrocal no tienen la menor huella de esos raíles (figura 10), algo incomprensible, pues el substrato es el mismo, las blandas pizarras y metagrauvacas. No porque falten esas huellas de las ruedas de los carruajes debe descartarse totalmente que sea un camino romano, ya que pueden corresponder a la tipología de un camino de herradura, que no deja rastros tan visibles como las huellas de los carros. Estos "carriles" son más anchos y las huellas de paso unas veces discurren por el centro de la calzada y otras por los laterales, y muchas ocasiones forman pronunciados escalones, propios del paso de caballerías.

Dado que existe documentación sobre un importante camino que atraviesa toda esta zona en 


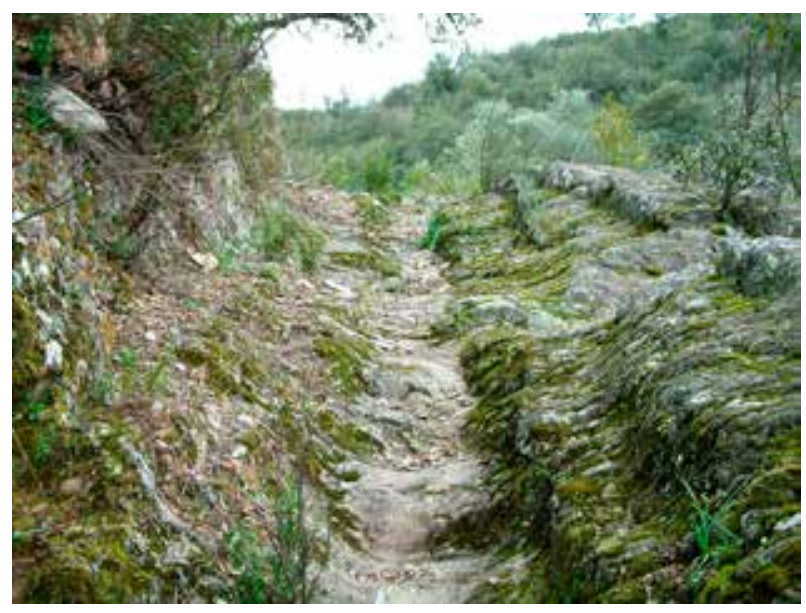

Figura 10. Trinchera del Camino del Moro en Berrocal.

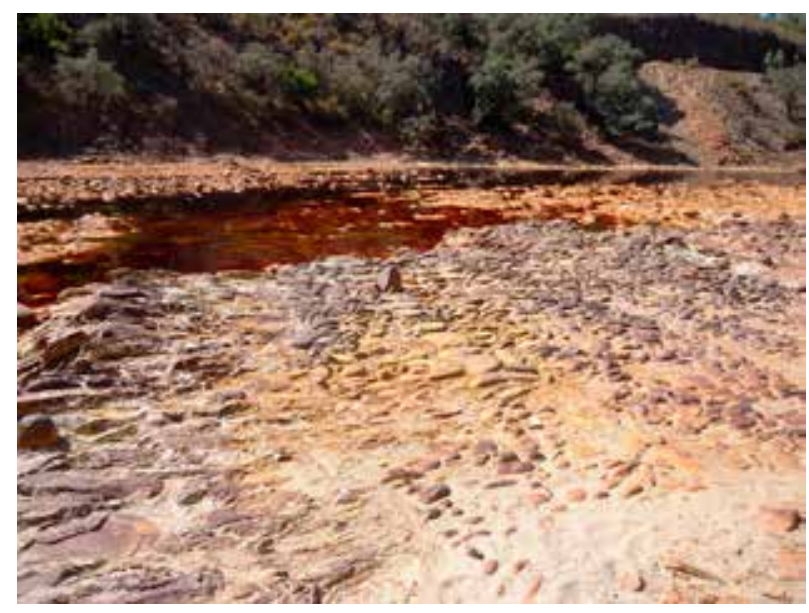

Figura 11. Pasada del Molino Viejo sobre el río Tinto en el Camino del Moro (Berrocal).

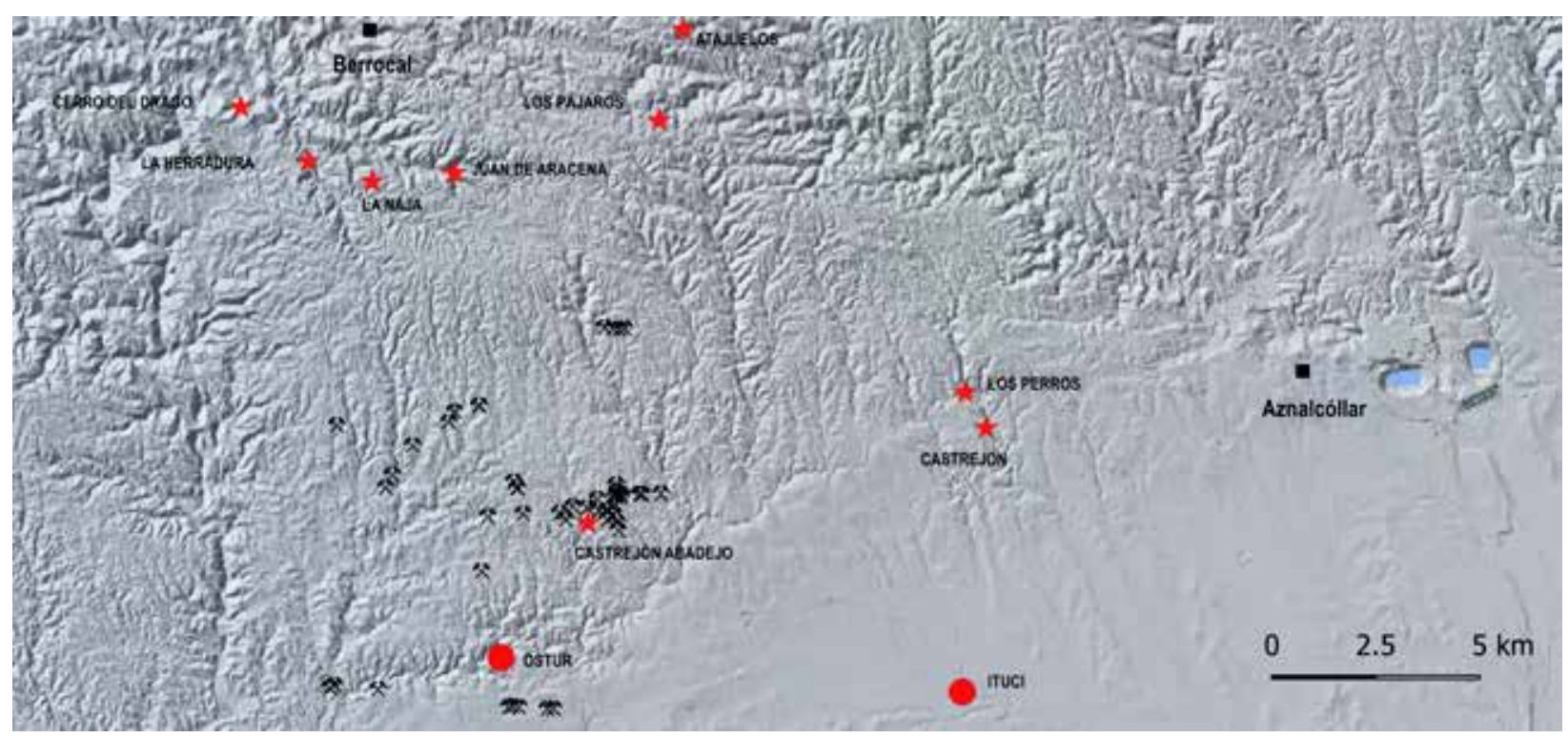

Figura 12. Fortificaciones romanas de la Sierra de Tejada y su entorno minero.

época moderna, a día de hoy creemos que estos restos pueden identificarse con el mismo. Este camino a parece recogido en la cartografía militar de España (escala 1.50.000) como Vereda de Portugal. El camino alcanza Berrocal desde el término de Zalamea, a donde llegaba desde Calañas a partir de la Ermita de Santa María, pasaba por la parte meridional de la Sierra del Águila y atravesaba el río Tinto a la altura del Molino Viejo, en el que se conserva una pasada empedrada (figura 11); desde aquí toma por la espalda del Pico del Drago, Cumbre de las Cuestas del Carril y Cuesta del Carril, y baja a la campiña atravesando el río Corumbel a la altura de la Pasada de Zalamea, un topónimo que seguramente tiene que ver con la dirección de este camino. Hay que tener en consideración que algunos caminos romanos y aún medievales o modernos aparecen en la cartografía actual como veredas de carne, una senda con claras connotaciones de paso de ganado, pero en realidad corresponden a antiguos caminos de herradura, pues la anchura de su trazado según las trincheras que va formando no sobrepasa los 2,5 $\mathrm{m}$. La verdad es que este camino no se dirige a Riotinto ni llega siquiera a Berrocal, sino que cruza el río Tinto más abajo para orientarse hacia la zona de Calañas. El verdadero camino de herradura a Riotinto se conserva en la Rivera de Cachán, aguas arriba del río Tinto, donde toma la dirección de la 
aldea de Las Delgadas (Zalamea la Real). Una obra de estas características, con trincheras bien labradas y pasadas muy bien construidas requirieron de un enorme esfuerzo en mano de obra y financiación, por lo que su momento de construcción se asoció a época romana, el momento de mayor bonanza económica de las minas de la región, una época de gran rendimiento económico que justificaría su costosa ejecución. Este camino ofrecía una alternativa a la comunicación de Sevilla con Lisboa, y en los repertorios de Villuga se lleva por Sanlúcar la Mayor, Paymogo, Serpa, Cuba, Torrão, Alcacer do Sal, Palma, Marateca, Palmela, Almada y Lisboa (Villuga, 1546). En los Itinerarios Militares de Caminos del siglo XIX también se recogen caminos que atraviesan la Sierra de Tejada, como el de Sanlúcar la Mayor a Aracena por Minas de Riotinto, que pasa por el Cortijo de Chichina, vadea el Arroyo de Barbacena, y sigue por las huertas de Tejada, Las Navas, Berrocal, Las Delgadas, Montesoromero, Minas de Riotinto y Aracena (AA.VV., 1866, 330, n 920).

A modo de conclusión hay que señalar que la exploración minera de este sector de minas filonianas y los caminos que cruzan la Sierra de Tejada para comunicar las campiñas de la depresión del Guadalquivir con las tierras del suroeste peninsular, deben ser los principales motivos del plan de fortificación que hemos descrito en párrafos anteriores. En definitiva, la defensa de un territorio estratégico que una vez que fue explorado ya no lo fue tanto, lo que motivo el abandono de las fortificaciones.

BiBLIOGRAFÍA.

AA.VV (1866), Itinerario Militar de España, V. Granada, Andalucía y Extremadura. M. Rivadeneyra impresor, Madrid.

Alarcão, C., Carvalho, P. y Gonçalves, A. -Coords.(2010), Castelo da Lousa. Intervenções arqueológicas de 1997 a 2002, Studia Lusitana 5 , Mérida.

Blanco, A. y Rothenberg, B. (1981), Exploración Arqueometalúrgica de Huelva, Barcelona.

Brotóns, F. y Murcia, A. J. (2008), "Los castella tardorrepublicanos romanos de la cuenca alta de los ríos Argos y Quípar (Caravaca, Murcia). Aproximación arqueológica e histórica”, Del Imperium de Pompeyo a la Autoritas de Augusto, Homenaje de Machael Grant, Mª P. García Bellido, A. Mostalac y A. Jiménez (Eds.), Anejos de Archivo Español de Arqueología,
XLVII, 49-66.

Canto, A.M" (1979), "El acueducto romano de Itálica”, Madrider Mitteilungen, 20, 282-338.

Domergue, C. (1983), La mine antique d'Aljustrel (Portugal) et les Tables de Bronze de Vipas$c a$, Paris.

Domergue, C. (1990), Les mines de la Péninsule Ibérique dans l'Antiquité romaine, École Française de Rome, Roma.

González, J. y Pérez, J. A. (1986), "La Romanización”, Huelva y su Provincia, II, Cádiz, 249299.

Gonzalo y Tarín, J.(1888), Descripción física, geológica y minera de la provincia de Huelva, Memorias de la Comisión del Mapa Geológico de España, Madrid.

Gutiérrez Soler, L.M. (2010), "Los Castilletes de Sierra Morena”, Minería Antigua en Sierra Morena, Jaén, 67-104.

Fabião, C. (2002), "Os chamados castella do sudoeste, arquitectura, cronologia e funções”, $A r$ chivo Español de Arqueología, 75, 177-193.

Fernández Jurado, J. (1989), Tejada la Vieja, ciudad protohistórica, Huelva Arqueológica, IX. Huelva.

Heras Mora, F.J. (2018), La implantación militar romana en el suroeste hispano (siglos II-I a.n.e.), Anejos de Gladius, Madrid.

Hunt Ortiz, M. (1995), "El foco metalúrgico de Aznalcóllar, Sevilla. Técnicas analíticas aplicadas a la arqueometalurgia del Suroeste de la Península Ibérica”, Tartessos 15 años después (19681993), Jerez de la Frontera, 447-473.

Hunt Ortiz, M. (2003), Prehistoric Mining and Metallurgy in South West Iberian Península, B.A.R. International Series, 1118, Oxford.

Maia, M. (1986), "Os castella do Sul de Portugal”, Madrider Mitteilungen, 27, 195-223.

Mataloto, R. (2002), "Fortins e recintos-torre do Alto Alentejo: antecâmara da romanização dos campos”, Revista Portuguesa de Arqueología, 5/1,161-220.

Mataloto, R., Mayoral, V. y Roque, C. -Eds.-(2014), La gestación de los paisajes rurales entre la Prehistoria y el período romano. Formas de asentamiento y procesos de implantación, Anejos de Archivo Español de Arqueología, LXX, Mérida.

Mayoral Herrera, V. (2018), Fortificaciones, recintos ciclópeos y proceso de romanizacioón en la comarca natural de La Serena (Siglos II 
A.C. al I D. C.), Mérida.

Mayoral, V. y Celestino, S. -Eds.- (2010), Los paisajes rurales de la romanización. Arquitectura y explotación del territorio, Badajoz.

Mayoral, V., Celestino, S., Sala, E. y Bustamante, M. (2011), "Fortificaciones e implantación romana entre La Serena y la vega del Guadiana: El Castejón de Las Merchanas (Don Benito, Badajoz)", Archivo Español de Arqueología, 84, 87-118.

Moreno, C., González, F. y Sáez, R. (2009), "La provincial de Huelva desde una perspectiva geológica", Geología de la provincia de Huelva, Huelva, 5-7.

Moret, P. (1999), "Casas fuertes romanas en la Bética y Lusitania”, Economie et territorie en Lusitanie romaine, Madrid, 55-89.

Moret, P. y Chapa, T. - Eds.- (2004), Torres Atalayas y Casas Fortificadas. Explotación y Control del Territorio, Jaén.

Morín, J., De Almeida, R., Barroso, R. y López, F.J. (2010), El yacimiento de Pozo Sevilla (Alcázar de San Juan, Ciudad Real) ¿Un ejemplo de casa-torre en La Mancha?, Los paisajes rurales de la romanización. Arquitectura y explotación del territorio, V. Mayoral y S. Celestino, V. Mayoral y S. Celestino (Eds.),

Ortiz, P. y Rodríguez, A. (2004), "La Torre de Hijoviejo: génesis, evolución y contexto de un asentamiento fortificado en la Serena (Badajoz)", Torres, Atalayas y casas fortificadas. Explotación y control del territorio en Hispania (S. III a. de C.-S. I d. de C.), P. Moret y T. Chapas (Eds.), Jaén, 77-96.

Pradós, J. y Ruiz De Arbulo, J. -Eds.- (2015), Castella $i$ praesidia en la façana mediterránia de la Hispania tardorrepublicana, Revista d'Arqueología de Ponent, 25, Lleida.

Pera, J. y Vidal, J. -Eds.- (2016), Fortificaciones y control del territorio en la Hispania republicana, Zaragoza.

Pérez Macías, J.A. (2015a), “Augusto y los distritos mineros del suroeste”, Augusto y la Bética. Aspectos históricos y arqueológicos, C. Márquez y E. Melchor (Coords), Córdoba, 283-316.

Pérez Macías, J.A. (2015b), "Iter Urium-Onuba. La vía de Valverde del Camino, construcción, uso y entorno arqueológico", El Andévalo. Paisajes y Humanidad, Actas de las V Jornadas de $\mathrm{Pa}-$ trimonio de El Andévalo, Huelva, 105-150.

Pérez Macías, J.A. (2018), Fortificaciones roma- nas en el área minera de Huelva, Universidad de Huelva, Huelva.

Pérez, J.A. y Delgado, A. (2010), "El castellum de El Castillejo (El Campillo, Huelva): explotación romano-republicana en Riotinto", Río Tinto, Historia, Patrimonio Minero y Turismo Cultural, J.A. Pérez, A. Delgado, J.M. Pérez, y F. J. Delgado (Eds.), Huelva, 45-75.

Pérez, J.A. y Delgado, A. (2012), "Paisaje y territorio de Riotinto en época romana”, Paisajes mineros antiguos de la Península ibérica. Investigaciones recientes y nuevas lineas de trabajo, Homenaje a Claude Domergue (M. Zarzalejos, P. Hevia y L. Mansilla, Eds.), Madrid, 47-68.

Pinedo Vara, I. (1963), Las piritas de Huelva. Su historia, minería y aprovechamiento, Summa, Madrid.

Principal, J., Ñaco Del Hoyo, T., Durán, M. y Mestres, I.- Eds.- (2017), Roma en la Península Ibérica presertoriana. Escenarios de la implantación militar provincial, Col-lecció Instrumenta, 56, Barcelona.

Rufete Tomico, P. (2009), "El Castrejón. Un asentamiento de época romano-republicana”, Huelva Arqueológica, 22, 8-44.

Ruiz Acevedo, J. M. (1998), Las vías romanas en la provincia de Huelva, Huelva.

Ruiz Mata, D. (1995), "Las cerámicas del Bronce Final. Un soporte tipológico para delimitar el espacio y el tiempo tartéssico", Tartessos 25 años después, Jerez de la Frontera, 265-315.

Ruiz, D. y Fernández, J. (1988), El poblado metalúrgico de época tartéssica de San Bartolomé de Almonte (Huelva), Huelva Arqueológica, VIII, Huelva.

Sáez, R., Requena, A., Fernández-Caliani, J. C. y Ruiz De Almodóvar, G. (1989), "Control estructural de las mineralizaciones de Sn-W-As del Bajo Corumbel, La Palma del Condado, Huelva”, Studia Geologica Salmanticensia, 4, 189-203.

Sala, F., Moratalla, J. y Abad, L. (2014), "Los fortines de la costa septentrional alicantina: una red de vigilancia de la navegación”, Las guerras civiles romanas en Hispania. Una revisión histórica desde la Contestania (F. Sala y J. Morallata (Eds.), Alicante, 79-90.

Salkield, L.V. (1970), "Ancient slag in the south west of the Iberian peninsula", La minería 
Hispana e Iberoamericana. Contribución a su estudio, León, 85-99.

Tornos Arroyo, F. (2008), "La geología y la metalogenia de la Faja Pirítica Ibérica”, Macla, 10, 13-23.

Vidal Teruel, N. (1997), "La economía de Tejada la Nueva (Huelva) a través de las fuentes arqueológicas, numismáticas y textuales", Huelva en su Historia, 6, 31-45.

Villuga, P.J. (1546), Repertorio de Caminos de España (hasta ahora nunca visto), reimp. de G. Menéndez-Pidal y Goyri, 1951, Madrid. 
